\title{
Group B Streptococcus Sequence Type 283 Disease Linked to Consumption of Raw Fish, Singapore
}

\author{
Priyanka Rajendram, Win Mar Kyaw, \\ Yee Sin Leo, Hanley Ho, Wen Kai Chen, \\ Raymond Lin, De Partha Pratim, \\ Hishamuddin Badaruddin, Brenda Ang, \\ Timothy Barkham, Angela Chow
}

An outbreak of invasive group B Streptococcus (GBS) disease occurred in Singapore in mid-2015. We conducted a case-control study of 22 adults with invasive GBS infections during June 21-November 21, 2015. Consumption of raw fish was strongly associated with invasive sequence type 283 infections, but not with non-sequence type 283 infections.

Grouga roup B Streptococcus (GBS) disease is caused by $S$. agalactiae, a commensal bacterium that can be isolated from genitourinary and gastrointestinal tracts of up to $30 \%$ of healthy adults. GBS can cause skin and soft tissue infections, urinary tract infections, bacteremia, and meningitis in adults; pregnancy-associated infections can lead to invasive disease in newborns (1).

In mid-2015, an outbreak of invasive GBS disease was reported in acute-care hospitals in Singapore. An increase in GBS bacteremia rate was observed for all adult acutecare hospitals, including Tan Tock Seng Hospital (TTSH), a 1,600-bed adult tertiary-care hospital in central Singapore, which reported an increase in GBS bacteremia rate from 3.5 cases/month in January-December 2014 to 6.5 cases/month in January-June 2015. Some infected men and nonpregnant women reported consuming raw fish before infection.

On the basis of detection of GBS in fish samples during joint investigations by the National Environmental Agency, the Agri-Food and Veterinary Authority of Singapore, and the Ministry of Health, sales of raw fish dishes containing Asian bighead carp and snakehead fish were suspended on July 24, 2015 (during epidemiologic week 29) (2). Concurrently, serotyping of GBS isolates collected from hospitals showed an increase in serotype III, and multilocus sequence type 283 (ST283) was isolated from a

Author affiliations: Tan Tock Seng Hospital, Singapore

(P. Rajendram, W.M. Kyaw, Y.S. Leo, H. Ho, W.K. Chen,

D.P. Pratim, B. Ang, T. Barkham, A. Chow); National Public Health

Laboratory, Singapore (R. Lin); Ministry of Health, Singapore

(H. Badaruddin)

DOI: http://dx.doi.org/10.3201/eid2211.160252 patient with GBS meningitis (1). We conducted a study at TTSH to compare the epidemiology of invasive ST283 and non-ST283 infections and to assess factors associated with invasive ST283 infections.

\section{The Study}

We conducted a prospective case-control study (case:control ratio 1:3.5) of patients admitted to TTSH during June 21November 21, 2015 (epidemiologic weeks 25-46). Using a standardized, interviewer-administered questionnaire, we collected information on food exposure history, in particular consumption of raw or undercooked fish, beef, eggs, and vegetables, during the 2 weeks before admission. Information on demographics, clinical history, and laboratory results were obtained from medical records. All GBS isolates were sent to the National Public Health Laboratory and serotyped by PCR (3) and genotyped by multilocus sequence typing using a standard $S$. agalactiae strain (4).

We defined case-patients as inpatients at TTSH during epidemiologic weeks 25-46 who had laboratoryconfirmed GBS infections detected in samples from any sterile site (blood, synovial fluid, cerebrospinal fluid) (5) within 48 hours after admission (6). Controls were defined as inpatients at TTSH with negative culture results for any sterile site (i.e., without invasive disease) within 48 hours after admission. We compared characteristics, food and nonfood exposures, and clinical presentation of persons infected with ST283 with those infected with non-ST283 and controls (Table 1). We constructed a multivariable logistic regression model based on major variables of interest from univariable analysis to assess for independent factors associated with ST283 and non-ST283 infections (Table 2).

A total of 22 case-patients ( 17 with bacteremia, 2 with septic arthritis, and 3 with bacteremia complicated by meningitis, epidural space abscess, and septic arthritis) and 76 controls ( 73 provided blood, 2 provided joint fluid, 1 provided both) were included in this study. Among 22 case-patients, 11 had serotype III GBS infections, of whom 9 had ST283 infections. None of the other serotype III strains, namely ST17 (1) and a new ST not previously reported (1), were single-locus variants of ST283. Other serotypes not typed were Ia (3), II (5), V (2), and VII (1).

Most (8/9) ST283 infections were identified during epidemiologic weeks $25-29$, before suspension of 
Table 1. Characteristics of patients with invasive group B Streptococcus ST283 or non-ST283 infections and controls, Singapore*

\begin{tabular}{|c|c|c|c|c|c|c|}
\hline \multirow[b]{2}{*}{ Characteristic } & \multirow[b]{2}{*}{$\begin{array}{l}\text { ST283 } \\
\mathrm{n}=9\end{array}$} & \multirow[b]{2}{*}{$\begin{array}{c}\text { Non-ST283 } \\
n=13\end{array}$} & \multirow[b]{2}{*}{$\begin{array}{c}\text { Controls, } \\
\mathrm{n}=76\end{array}$} & \multicolumn{3}{|c|}{ Comparison and $p$ value } \\
\hline & & & & $\begin{array}{c}\text { ST283 vs. } \\
\text { non-ST283 }\end{array}$ & $\begin{array}{l}\text { ST283 vs. } \\
\text { controls }\end{array}$ & $\begin{array}{l}\text { Non-ST283 } \\
\text { vs. controls }\end{array}$ \\
\hline \multicolumn{7}{|l|}{ Demographic } \\
\hline Sampled during epidemiologic wk 25-29 & $8(88.9)$ & $3(23.1)$ & $37(48.7)$ & $<0.01$ & 0.02 & 0.09 \\
\hline Median age, y (IQR) & $59.4(25-70)$ & $74(46-88)$ & 77.5 (42-99) & 0.03 & 0.002 & 0.37 \\
\hline Age $<65$ y $\dagger$ & $7(77.8)$ & $3(23.1)$ & $18(23.7)$ & 0.01 & $<0.001$ & 0.96 \\
\hline Female sex† & $6(66.7)$ & $6(46.2)$ & $45(59.2)$ & 0.34 & 0.67 & 0.38 \\
\hline Chinese ethnicity $\dagger$ & $9(100.0)$ & $11(84.6)$ & $58(76.3)$ & 0.22 & 0.10 & 0.51 \\
\hline \multicolumn{7}{|l|}{ Concurrent condition } \\
\hline Diabetes mellitus $\dagger$ & $1(11.1)$ & $5(38.5)$ & $33(43.4)$ & 0.16 & 0.06 & 0.74 \\
\hline Malignancy† & $1(11.1)$ & $1(7.7)$ & $11(14.5)$ & 0.78 & 0.78 & 0.51 \\
\hline Cardiovascular disease $†$ & $1(11.1)$ & $4(30.8)$ & $29(38.2)$ & 0.28 & $<0.01$ & 0.61 \\
\hline Renal disease $\dagger$ & $1(11.1)$ & $2(15.4)$ & $25(32.9)$ & 0.77 & 0.18 & 0.20 \\
\hline Liver disease† & 0 & $2(15.4)$ & $5(6.6)$ & 0.22 & 0.43 & 0.28 \\
\hline Gastrointestinal disease $†$ & $1(11.1)$ & $2(15.4)$ & $14(18.4)$ & 0.77 & 0.59 & 0.79 \\
\hline Respiratory disease $\dagger$ & 0 & $2(15.4)$ & $16(21.1)$ & 0.22 & 0.13 & 0.64 \\
\hline Blood disorder† & 0 & $1(7.7)$ & $28(36.8)$ & 0.39 & 0.03 & 0.04 \\
\hline Skin wound $\dagger$ & 0 & $2(15.4)$ & $12(15.8)$ & 0.22 & 0.20 & 0.97 \\
\hline Charlson Comorbidity Score, median (range) & $0(0-9)$ & $2(0-7)$ & $3.5(0-12)$ & 0.21 & 0.03 & 0.26 \\
\hline Any concurrent condition & $3(33.3)$ & $11(84.6)$ & $69(90.8)$ & 0.01 & $<0.001$ & 0.50 \\
\hline Hospitalized during 6 mo before admission $\dagger$ & $2(22.2)$ & $6(46.2)$ & $31(40.8)$ & 0.25 & 0.28 & 0.72 \\
\hline \multicolumn{7}{|l|}{ Food history } \\
\hline $\begin{array}{l}\text { Ate raw or undercooked fish } \leq 2 \text { wk before } \\
\text { admissiont }\end{array}$ & $7(77.8)$ & 0 & $3(4.0)$ & $<0.001$ & $<0.001$ & 0.47 \\
\hline $\begin{array}{l}\text { Ate raw or undercooked beef } \leq 2 \mathrm{wk} \text { before } \\
\text { admission } \dagger\end{array}$ & $2(22.2)$ & 0 & 0 & 0.07 & $<0.001$ & NC \\
\hline Ate raw vegetables $†$ & $1(11.1)$ & 0 & $4(5.3)$ & 0.22 & 0.48 & 0.40 \\
\hline Ate raw eggs & 0 & 0 & $13(17.1)$ & $\mathrm{NC}$ & 0.18 & 0.11 \\
\hline \multicolumn{7}{|l|}{ Other exposure history } \\
\hline Fish-related activities (fishing, fish spa) $\dagger$ & 0 & 0 & 0 & $\mathrm{NC}$ & NC & $\mathrm{NC}$ \\
\hline \multicolumn{7}{|l|}{ Clinical presentation } \\
\hline Fever (temperature $\geq 38^{\circ} \mathrm{C}$ ) & $7(77.8)$ & $9(69.2)$ & $23(30.3)$ & 0.66 & $<0.01$ & $<0.01$ \\
\hline Musculoskeletal pain & $7(77.8)$ & $4(30.8)$ & $20(26.3)$ & 0.03 & $<0.01$ & 0.74 \\
\hline Fever and musculoskeletal pain & $5(55.6)$ & $3(23.1)$ & $8(10.5)$ & 0.12 & $<0.001$ & 0.20 \\
\hline$<2$ d between symptom onset and admission & $4(44.4)$ & $11(84.6)$ & $39(51.3)$ & 0.05 & 0.70 & 0.03 \\
\hline
\end{tabular}

sale of raw fish dishes. During epidemiologic weeks 30-46, only 1 ST283 case was identified, compared with $10(77 \%)$ of 13 of non-ST283 cases. Persons infected with ST283 tended to be younger than persons infected with non-ST283 (median age 59.4 years vs. 74.0 years) $(\mathrm{p}=0.033)$, and they were also less likely to have a preexisting medical condition $(33.3 \%$ vs. $84.6 \%$; p = $0.014)$. Seven (77.8\%) of 9 ST283-infected patients had eaten raw or undercooked fish $\leq 2$ weeks before admission, compared with 0 of non-ST283-infected patients $(p<0.001)$ and 3 controls $(p<0.001)$. Two of the ST283infected patients who had eaten raw or undercooked fish had also eaten raw or undercooked beef. ST283-infected persons were more likely than controls to have high fever (temperature $\geq 38^{\circ} \mathrm{C}$ ) and musculoskeletal pain $(55.6 \%$ vs $10.5 \%$; $<<0.001)$; however, this comparison was not significant for persons with non-ST283-infection $(23.1 \% ; \mathrm{p}=0.12)$. Only $45(60 \%)$ controls had a noninvasive infection.

Multivariate analysis showed that eating raw or undercooked fish during the 2 weeks before admission was independently associated with ST283 infection, but not with non-ST283 infection (Table 2), when compared with controls. None of the non-ST283-infected patients had eaten raw or undercooked fish during the timeline.

We also conducted a subanalysis that compared ST283-infected patients with onset up to epidemiologic week 29 with controls (who had similar infection onset

Table 2. Multivariable analysis of risk factors associated with invasive group B Streptococcus ST283 and non-ST283 infections, Singapore*

\begin{tabular}{|c|c|c|c|c|}
\hline \multirow[b]{2}{*}{ Factor } & \multicolumn{2}{|l|}{ ST283 } & \multicolumn{2}{|c|}{ Non-ST283 } \\
\hline & aOR $(95 \% \mathrm{Cl})$ & $p$ value & aOR $(95 \% \mathrm{Cl})$ & $p$ value \\
\hline $\begin{array}{l}\text { Consumption of raw or undercooked fish } \leq 2 \text { weeks before } \\
\text { hospitalization }\end{array}$ & $100.11(6.21-1612.91)$ & 0.001 & $\mathrm{NC}$ & $\mathrm{NC}$ \\
\hline Age $<65$ y & $13.34(1.14-156.56)$ & 0.04 & $1.04(0.25-4.27)$ & 0.96 \\
\hline Charlson Comorbidity Score & $1.02(0.63-1.64)$ & 0.95 & $0.85(0.65-1.11)$ & 0.23 \\
\hline
\end{tabular}

*Bold indicates statistical significance. aOR, adjusted odd ratio; NC, not calculable; ST, sequence type. 
and opportunity to purchase and eat raw fish). We observed a stronger association with eating raw fish among persons who could purchase raw fish dishes (adjusted odds ratio $12,423.62,95 \%$ CI 1.51 to $1.02 \times 10^{8} ; \mathrm{p}=$ 0.04). However, 2 of the ST283-infected patients did not report eating raw fish, which suggests other means of acquiring ST283 infections.

\section{Conclusions}

Several population-based studies have raised concerns about the increasing incidence of invasive GBS disease in men and nonpregnant women $(7,8)$. We report an outbreak of invasive GBS serotype III ST283 infections in men and nonpregnant women. Molecular epidemiology studies have showed that ST283 strains from fish in Asia had the same virulence gene profile as human invasive isolates, which suggests potential exposure of humans and fish to common environmental sources of ST283 or transmission of the bacterium between different host species (9). Fish consumption was associated with an increased risk for acquisition of GBS in a prospective cohort study in the United States (10). However, data are limited for the likelihood and routes of interspecies transmission of this strain associated with fish and invasive disease in humans.

We found a strong association between consumption of raw or undercooked fish and invasive ST283 infections in men and nonpregnant women. Being older and having severe concurrent conditions were negatively associated with infection, contrary to findings in previous studies $(11,12)$. Our findings suggest that non-ST283 strains caused symptomatic infection in more susceptible populations (those with more concurrent conditions), whereas ST283 might be more invasive and affected less susceptible persons.

An additional contributing factor could be differences in food consumption in local populations; elderly persons and those with severe concurrent conditions might avoid eating raw or undercooked foods (13). The finding that no non-ST283-infected patients had eaten raw or undercooked fish before admission strengthened our hypothesis of a link between the ST283 and consumption of raw or undercooked fish.

After isolation of ST283 from 4\% of freshwater fish samples from restaurants, markets, stores, and fisheries, use of freshwater fish in all ready-to-eat raw fish dishes sold at retail food establishments was banned in Singapore on December 5, 2015 (14,15). The number of reported invasive GBS infections in Singapore has decreased, although sporadic invasive ST283 infections have been identified. TTSH has seen no new invasive ST283 infections identified since the study ended on November 21, 2015, despite continued active case-finding.
The relatively small number of ST283 and non-ST283 infections in this study is a limitation that precludes drawing definitive conclusions. However, isolation of ST283 from fish samples, the strong association of raw fish consumption with ST283 infection, and the sharp decrease of ST283 infections after the food ban strongly suggest a food-related outbreak. Although the outbreak of GBS disease in Singapore has been controlled, further studies on the virulence, transmissibility, and epidemiology of ST283 and risk factors are warranted to better manage future infections.

Dr. Rajendram is a medical resident in the National Preventive Medicine Residency Program in Singapore. Her research interests are health communication and risk/crisis management during outbreaks or other health-related events.

\section{References}

1. Mehershahi KS, Hsu LY, Koh TH, Chen SL. Complete genome sequence of Streptococcus agalactiae serotype III, multilocus sequence type 283 strain SG-M1. Genome Announc. 2015;3:e01188-15.

2. Ministry of Health. Singapore. Update on investigation into group B streptococcus cases. Press releases, news highlights, July 24, 2015 [cited 2016 Aug 4] https://www.moh.gov.sg/content/ moh_web/home/pressRoom/pressRoomItemRelease/2015/updateon-investigation-into-group-b-streptococcus-cases.html

3. Yao K, Poulsen K, Maione D, Rinaudo CD, Baldassarri L, Telford JL, et al.; Members of the DEVANI Study Group. Capsular gene typing of Streptococcus agalactiae compared to serotyping by latex agglutination. J Clin Microbiol. 2013;51:503-7. http://dx.doi.org/10.1128/JCM.02417-12

4. Jolley KA, Maiden MC. BIGSdb: scalable analysis of bacterial genome variation at the population level. BMC Bioinformatics. 2010;11:595. http://dx.doi.org/10.1186/1471-2105-11-595

5. Blancas D, Santin M, Olmo M, Alcaide F, Carratala J, Gudiol F. Group B streptococcal disease in nonpregnant adults: incidence, clinical characteristics, and outcome. Eur J Clin Microbiol Infect Dis. 2004;23:168-73. http://dx.doi.org/10.1007/s10096-003-1098-9

6. Ho CM, Chi CY, Ho MW, Chen CM, Liao WC, Liu YM, et al. Clinical characteristics of group B Streptococcus bacteremia in non-pregnant adults. J Microbiol Immunol Infect. 2006; 39:396-401.

7. Teatero S, McGeer A, Li A, Gomes J, Seah C, Demczuk W, et al. Population structure and antimicrobial resistance of invasive serotype IV group B Streptococcus, Toronto, Ontario, Canada. Emerg Infect Dis. 2015;21:585-91. http://dx.doi.org/10.3201/ eid2014.140759

8. Farley MM, Harvey RC, Stull T, Smith JD, Schuchat A, Wenger JD, et al. A population-based assessment of invasive disease due to group B Streptococcus in nonpregnant adults. N Engl J Med. 1993;328:1807-11. http://dx.doi.org/10.1056/ NEJM199306243282503

9. Delannoy CM, Crumlish M, Fontaine MC, Pollock J, Foster G, Dagleish MP, et al. Human Streptococcus agalactiae strains in aquatic mammals and fish. BMC Microbiol. 2013;13:41. http://dx.doi.org/10.1186/1471-2180-13-41

10. Foxman B, Gillespie BW, Manning SD, Marrs CF. Risk factors for group B streptococcal colonization: potential for different transmission systems by capsular type. Ann Epidemiol. 2007; 17:854-62. http://dx.doi.org/10.1016/j.annepidem. 2007.05.014 
11. Trivalle C, Martin E, Martel P, Jacque B, Menard JF, Lemeland JF. Group B streptococcal bacteremia in the elderly. J Med Microbiol. 1998;47:649-52. http://dx.doi.org/10.1099/ 00222615-47-7-649

12. Camuset G, Picot S, Jaubert J, Borgherini G, Ferdynus C, Foucher A, et al. Invasive group B streptococcal disease in non-pregnant adults, Réunion Island, 2011. Int J Infect Dis. 2015;35:46-50. http://dx.doi.org/10.1016/j. ijid.2015.04.006

13. Kendall PA, Hillers VV, Medeiros LC. Food safety guidance for older adults. Clin Infect Dis. 2006;42:1298-304. http://dx.doi.org/10.1086/503262

14. National Environment Agency. Singapore. Freshwater fish banned from ready-to-eat raw fish dishes, news releases, December 5, 2015 [cited 2016 Aug 4]. http://www.nea.gov.sg/corporate-functions/ newsroom/news-releases/freshwater-fish-banned-from-ready-toeat-raw-fish-dishes

15. The Straits Times. Singapore. GBS bacteria found in two types of fish: what you need to know about them, news report, July 27, 2015 (updated April, 29, 2016) [cited 2016 Aug 4]. http://www. straitstimes.com/singapore/health/gbs-bacteria-found-in-two-typesof-fish-what-you-need-to-know-about-them-0

Address for correspondence: Yee Sin Leo Institute of Infectious Diseases and Epidemiology, Tan Tock Seng Hospital, 11 Jalan Tan Tock Seng, 308433 Singapore; email: yee_sin_leo@ttsh.com.sg

\section{etymologia}

\section{Streptococcus [strep"to-kok'əs]}

$\mathrm{F}$ rom the Greek streptos ("chain") + kokkos ("berry"), streptococcal diseases have been known since at least the 4th century BCE when Hippocrates described erysipelas (Greek for "red skin"). The genus Streptococcus was named by Austrian surgeon Theodor Billroth, who in 1874 described "small organisms as found in either isolated or arranged in pairs, sometimes in chains" in cases of erysipelas or wound infections. Over subsequent decades, as microscopy and staining techniques improved, many different researchers characterized the bacteria now known as Streptococcus pyogenes (Lancefield group A $\beta$-hemolytic streptococcus), $S$. pneumoniae, and other species.

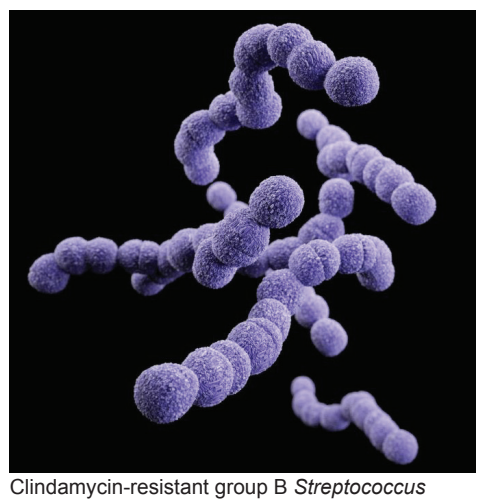

Clindamycin-resistant group B Streptococcus
Photo: Centers for Disease Control and Prevention

\section{Source}

1. Majno G, Joris I. Billroth and Penicillium. Rev Infect Dis. 1979;1:880-4. http://dx.doi.org/10.1093/ clinids/1.5.880

Address for correspondence: Ronnie Henry, Centers for Disease Control and Prevention, 1600 Clifton Rd NE, Mailstop E03, Atlanta, GA 30329-4027, USA; email: boq3@cdc.gov

DOI: http://dx.doi.org/10.3201/eid2211.ET2211 